\title{
Study on Evolution of Cybercrime
}

\author{
Robert-Cristian VOICULESCU \\ "Alexandru Ioan Cuza" Police Academy, Bucharest, Romania \\ cleryc_91@yahoo.com
}

\begin{abstract}
In the following article we will see how cybercrime has evolved over the years, how it began from simple attacks which had no purpose other than inconveniencing those who were attacked, and led to the major crimes we see today, such as identity theft, frauds, child pornography and even terrorist attacks, that cause numerous problems for individuals, institutions and even countries.

Furthemore, we will attempt to analyze the main ways in which cybercrime is realized, who are the people who engage in such activities, the means that they use in their efforts and how the authorities struggle to limit this phenomenon and put a stop to these attacks by bringing those who commit them to justice.

Last but not least, we will try and comprehend how big is the threat of cybercrime at the moment and how it will threaten us in the years to come, how will the rapid advance in technology influence this relatively new type of crime and what even greater risks we will be exposed to in the future.

Keywords: cybercrime, malware, cybercriminal

\section{References}

[1]. http://www.global-economic-symposium.org/knowledgebase/the-globalpolity/cybercrime-cybersecurity-and-the-future-of-the-internet/proposals/dealing-withcyber-crime-2013-challenges-and-solutions

[2]. http://www.fbi.gov/about-us/investigate/cyber

[3]. http://www.interpol.int/Crime-areas/Cybercrime/Cybercrime

[4]. http://www.criminalitatea-informatica.ro/

[5]. http://www.criminallawyergroup.com/criminal-defense/the-evolution-of-cybercrimefrom-past-to-the-present.php

[6]. http://xlgroup.com/ /media/fff/pdfs/cyberliability_xl
\end{abstract}

